\title{
Erratum to: Population-Based Comparison of Biomarker Concentrations for Chemicals of Concern Among Latino- American and Non-Hispanic White Children
}

\author{
M. E. Perla $\cdot$ Tessa Rue $\cdot$ Allen Cheadle $\cdot$ \\ James Krieger · Catherine J. Karr
}

Published online: 3 July 2014

(c) Springer Science+Business Media New York 2014

\section{Erratum to: J Immigrant Minority Health \\ DOI 10.1007/s10903-014-0002-2}

The original version of this article unfortunately contained an error in one of the coauthors' middle name.

The author name should be Catherine J. Karr (CJ Karr); instead, it is published as CK Karr.

The online version of the original article can be found under doi:10. 1007/s10903-014-0002-2.

M. E. Perla $(\bowtie) \cdot$ A. Cheadle $\cdot$ J. Krieger

Department of Health Services, School of Public Health, University of Washington, Box 357236, Seattle, WA 98195, USA

e-mail: mperla@uw.edu

A. Cheadle

e-mail: cheadle@uw.edu

J. Krieger

e-mail: james.krieger@kingcounty.gov

T. Rue

Center for Biomedical Statistics, University of Washington, Seattle, WA 98195, USA

e-mail: ruet@uw.edu

\author{
J. Krieger \\ Public Health - Seattle and King County, Chinook Building, \\ Suite 900, 401 5th Ave, Seattle, WA 98104, USA \\ C. J. Karr \\ Department of Environmental and Occupational Health \\ Sciences, School of Public Health, University of Washington, \\ Seattle, WA 98195, USA \\ e-mail: ckarr@uw.edu \\ C. J. Karr \\ Department of Pediatrics, School of Medicine, University of \\ Washington, Seattle, WA 98195, USA
}

